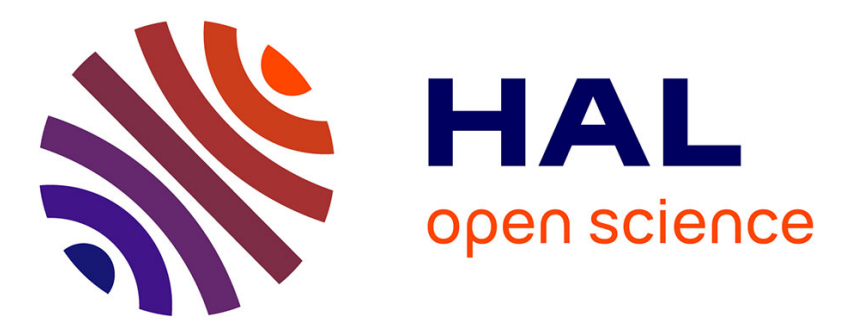

\title{
Muscle strength and metabolism in master athletes
}

Julien Louis, Christophe Hausswirth, François Bieuzen, Jeanick Brisswalter

\section{To cite this version:}

Julien Louis, Christophe Hausswirth, François Bieuzen, Jeanick Brisswalter. Muscle strength and metabolism in master athletes. International Journal of Sports Medicine, 2009, 30 (10), pp.754-759. 10.1055/s-0029-1231046 . hal-01713200

\section{HAL Id: hal-01713200 https: / hal-insep.archives-ouvertes.fr/hal-01713200}

Submitted on 20 Feb 2018

HAL is a multi-disciplinary open access archive for the deposit and dissemination of scientific research documents, whether they are published or not. The documents may come from teaching and research institutions in France or abroad, or from public or private research centers.
L'archive ouverte pluridisciplinaire HAL, est destinée au dépôt et à la diffusion de documents scientifiques de niveau recherche, publiés ou non, émanant des établissements d'enseignement et de recherche français ou étrangers, des laboratoires publics ou privés. 
paru dans : International journal of sports medicine, 2009, vol. 30, n¹0, oct., pp. 754-759

$5{ }^{1}$ Sport Ergonomy and Performance Laboratory, Handibio, EA 4322, University of Toulon-Var, 6 Av. De l'Université, BP 20132, 83957 La Garde Cedex - France.

$7 \quad 2$ Institut National du Sport et de L’Education Physique (INSEP), Laboratoire de Biomécanique 8 et de Physiologie, 11 Avenue du Tremblay, Paris 75012, France.

13 Corresponding author:

14 Pr. Brisswalter Jeanick

$15{ }^{1}$ Sport Ergonomy and Performance Laboratory, Handibio, EA 4322, University of Toulon-Var, 16 Av. De l'Université, BP 20132, 83957 La Garde Cedex - France

$17 \bowtie$ Email: brisswalter@univ-tln.fr

18 Tel: +33494142948

19 Fax: +33494142278

20

21 


\section{Muscle strength and metabolism in master athletes}

27 ABSTRACT

Knee extensor muscle strength and metabolism were examined in endurance trained 29 young versus master athletes (10 elderly: $63.1 \pm 2.3 \mathrm{yr}$ and 10 young : $28.7 \pm 3.2 \mathrm{yr}$ ). Before and 30 immediately after a resistance strength training (RST) session, subjects performed maximal

31 isometric voluntary contraction (MVC) and a 10-min cycling test at a moderate intensity. During

32 MVC, evoked contractions of the knee extensor muscles were performed to assess 33 neuromuscular properties. Metabolism was assessed using oxygen uptake kinetics model. 34 Before the RST session, master athletes show lower knee extensors MVC than young subjects 35 without any difference in oxygen uptake kinetics. After the RST session, a similar effect of 36 fatigue was observed on muscular properties and oxygen uptake kinetics whatever the group.

37 Our results suggest the ability of master athletes to perform exercise at a given intensity is 38 maintained despite a significant loss in strength with ageing. 
42 In the recent years there has been an increased interest in issues related to the enhancement of the 43 performance of master athletes [12, 26, 37, 39]. Many of the changes in physiological functional 44 capacity related to ageing have been found to be the result of long standing sedentary lifestyle 45 [26]. Studies on master athletes' performance have shown that master athletes are able to 46 maintain high performance as the age related structural adaptations are maintained in masters 47 athletes [26, 36, 37, 39]. The majority of studies working on the effect of age on the muscular 48 function have shown an impairment of the maximal force-generating capacities in elderly 49 compared to young adults and several factors have been identified [5, 20, 27]. For non endurance 50 trained adults, this reduction is generally attributed to a loss of muscle fibres, change in the 51 proportions of muscle fibre types [25, 33], and a reduction in muscle volume and cross-sectional 52 area [15]. Based on results of Coggan et al. [10] confirmed by Tarpenning et al. [38] decreases of 53 strength capacities for masters athletes could be explained by other factors. Indeed, these authors 54 have shown that fibre area and fibre distribution are maintained with aging for master runners. 55 They suggested that the decline in muscle performance may also be the result of neural factors, 56 such as muscle recruitment and/or specific tension. Within this framework, recent studies have 57 highlighted the interest to study age related fatigability during exercise to explain mechanisms 58 underlying the force decline with ageing, but to date contradictory results have been reported 59 mainly related to task dependency of fatigue $[2,14,19]$. Therefore, during the last decade, a 60 great attention has been attributed on the need to identify factors affecting muscle performance 61 decrease and strategies to increase muscle performance in older population [4, 11, 37]. Within 62 this framework (repetition avec ligne 35), it has been demonstrated that resistance training has a 
63 significant effect on muscle mass and force whereas endurance training increases oxygen 64 transport and consumption capacities in elderly subjects but little is known on the effect of 65 regular endurance training on muscle performance $[11,38]$.

66 Muscular performance alterations can be analyzed with isometric or dynamic maximal voluntary 67 contraction (MVC) performed before and after a fatiguing protocol [21, 22, 23]. In addition, 68 changes in locomotion efficiency can be evaluated during dynamic exercise like cycling by 69 analyzing oxygen uptake $[16,24]$. In these last studies efficiency is classically recorded from 70 steady state values of oxygen uptake during a submaximal exercise. During the last decade it has 71 been well documented that the characteristics of $\mathrm{VO}_{2}$ kinetics could reflect more accurately the 72 aerobic response to exercise and therefore efficiency [4, 7, 18]. During exercises above lactate 73 threshold $\mathrm{VO}_{2}$ increases with bi-exponential kinetics with a $\mathrm{VO}_{2}$ slow component [41]. It has

74 been demonstrated that $\mathrm{VO}_{2}$ kinetics get slower with age indicating a limitation in oxygen 75 delivery or in muscle oxidation activity and that the $\mathrm{VO}_{2}$ slow component amplitude is lower 76 indicating changes in muscle function $[3,4,9,35]$.

77 The analysis of ageing on muscular performance or efficiency is difficult to interpret because of 78 the confounding effects of reduction in physical activity levels, changes in body composition and 79 development of clinical diseases [37]. Therefore, the purpose of this study was to examine the 80 age-related alterations in neuromuscular properties and oxygen uptake kinetics in regularly 81 endurance-trained subjects. In this specific population we raised the following questions a) Do 82 endurance-trained master athletes present lower values of muscle strength and slower oxygen 83 uptake kinetics than young adults as classically described in the literature for untrained groups?

84 b) Is this possible difference enhanced by fatiguing exercise? 
SUBJECTS AND OVERALL DESIGN. - The investigation was conducted on 10 masters (Age, $62.5 \pm$

$874.1 \mathrm{yr}$ yr; height, $1.70 \pm 0.02 \mathrm{~m}$; body mass, $70.2 \pm 1.5 \mathrm{~kg}$, free fat mass, $22.4 \pm 0.8 \%$ ) and on 10

88 young men (Age, $26.2 \pm 2.4 \mathrm{yr}$, height, $1.82 \pm 0.05 \mathrm{~m}$; body mass, $74.4 \pm 5.2 \mathrm{~kg}$, free fat mass,

$8915.3 \pm 1.2 \%)$. All subjects had to be free from present or past neuromuscular conditions that

90

91

92

93

94

95

96

97 could affect motor function. Subjects were fully informed about the protocol, and informed consent was obtained prior to all testing. This study was approved by a local research ethics committee. The individuals selected were regularly trained subjects engaged in cycling and running long distance competitions (minimum training time per week: $6 \mathrm{hr}$ cycling and $1 \mathrm{hr}$ running). In both groups, all subjects were selected to have a similar training volume to avoid a possible training volume effect on the comparison between groups. Each subject completed three laboratory-based testing sessions separated by at least a 48 hour rest period (figure 1).

DETERMINATION OF $\mathrm{VO}_{2 M A X}$ - On their first visit to the laboratory the subjects underwent an incremental cycling test at a self-selected cadence on an electromagnetically braked ergocycle (Excalibur sport, Lode, Gröningen, The Nederland). The test began with a warm-up lasting 6 min of $100 \mathrm{~W}$ for young and $70 \mathrm{~W}$ for masters, after which the power output was increased by $30 \mathrm{~W}$ each minute until the subjects were exhausted. The criteria used for the determination of $\mathrm{VO}_{2 \max }$ were a plateau in $\mathrm{VO}_{2}$ despite an increase in workrate and a respiratory exchange ratio (RER) above 1.1. $\mathrm{V}_{\mathrm{E}}$ (minute ventilation) and $\mathrm{VO}_{2}$ were recorded using the Cosmed $\mathrm{K} 4 \mathrm{~b}^{2}$ telemetric system (Rome, Italy). Ventilatory thresholds ( $\mathrm{VT}_{1}$ and $\left.\mathrm{VT}_{2}\right)$ were assessed from the graph of $\mathrm{VE} / \mathrm{VO}_{2}$ relative to $\mathrm{VO}_{2}[34,40]$ 
CONTROL EXERCISE AND IRM KNEE EXTENSION EVALUATION - On their second visit to the

107 laboratory the subjects underwent a $10 \mathrm{~min}$ control cycling test (CTRL) at a self-selected

108 cadence on the same ergocycle at a load corresponding to: $\mathrm{P}_{\text {exercise }}=[$ Power output corresponding

109 to $\mathrm{VT}_{1}\left(\mathrm{PVT}_{1}\right)+$ Power output corresponding to the $\left.\mathrm{VT}_{2}\left(\mathrm{PVT}_{2}\right)\right] / 2$. Immediately before

$110\left(\mathrm{MVC}_{\mathrm{Ctrl}}\right)$ and after $\left(\mathrm{MVC}_{\mathrm{Ctrl}}\right.$ Post $)$ the control cycling test, subjects were placed in a seated

111 position and were securely strapped into the test chair to perform maximal voluntary isometric

112 (MVC) knee extension of their dominant leg using an isometric ergometer (Type: Schnell

113 Trainingsgeräte $\mathrm{GmbH}$, Peutenhausen, Germany). Subjects performed three MVC of short 114 duration $(2-3 \mathrm{sec})$ of the knee flexor and extensor muscles. A $60 \mathrm{sec}$ period of rest was imposed 115 between each contraction. The best performance of to the three trials was selected as the 116 maximal isometric voluntary contraction (MVC, in Newton).

117 One hour after end of the previous test, subjects were evaluated for their 1RM during inertial 118 knee extension exercise on a leg ergometer (Type: Schnell Trainingsgesäte GmbH, 119 Peutenhausen, Deutschland) The one repetition maximum (1RM), is defined as the load for 120 which only one full repetition, i.e., a sequence of movements ending back in the starting position, 121 can be performed. Determination of 1RM proceeds over subsequent trials in which the amount of 122 weight to be lifted is increased stepwise until the subject fails to produce a full-range movement 123 using method described by Bishop et al. [6]

124 RESISTANCE STRENGTH TRAINING SESSION AND CYCLING EXERCISE - On their third visit to the 125 laboratory the subjects had to perform a classical resistance strength training session composed 126 of 10 sets of 10 repetitions on a horizontal leg press (Technogym, Gambettola, Italy), at an 127 intensity of $70 \%$ of the individual one repetition maximum (1 RM). The rest between sets was 
128 90-s. The exercise consisted of a $3 \mathrm{sec}$ concentric contraction followed by a $3 \mathrm{sec}$ eccentric 129 contraction. After resistance strength training session, all subjects performed 10 min of cycling 130 on the electromagnetically braked ergocycle at intensity equal to that of the control test.

131 Before $\left(\mathrm{MVC}_{\text {Fatigue Pre }}\right)$ and after $\left(\mathrm{MVC}_{\text {Fatigue Post }}\right)$ the resistance strength training session, and 132 after the cycling exercise $\left(\mathrm{MVC}_{10-\mathrm{min}}\right.$ Post $)$, subjects performed three MVC of the knee extensor 133 muscles.

For each subject and each session, breath-by-breath data were time-aligned. Resting data were 136 obtained by averaging the values recorded over the $3 \mathrm{~min}$ rest period prior to exercise. $\mathrm{VO}_{2}$ 137 kinetics were determined by the use of a bi-exponential model of the form

$$
Y(t)=Y(b)+A_{1}^{*}\left[1-e^{(t-T D 1 / \tau 1)}\right]+A_{2}^{*}[1-e-(-T D 2 / \tau 2)]
$$

141 where $\mathrm{Y}$ represents $\mathrm{VO}_{2}$ at any time $(\mathrm{t}), \mathrm{b}$ is the baseline value of $\mathrm{Y}\left(\mathrm{VO}_{2 \mathrm{~b}}\right), \mathrm{A}_{1}$ and $\mathrm{A}_{2}$ represent

142 the primary and slow component amplitudes, 1 and 2 the time constants defined as the 143 duration of time through which $\mathrm{Y}$ increase to a value equivalent to $63 \%$ of $\mathrm{A}_{1}$ and $\mathrm{A}_{2}$, and $\mathrm{TD}_{1}$ 144 or $\mathrm{TD}_{2}$ are the time delays [7].

\section{EVOKED CONTRCATIONS}

146 The contractile properties (muscular twitch) of the quadriceps muscle were studied using 147 electrically evoked contractions. Electrical stimulation was applied to the femoral nerve of the 148 dominant leg according to the methodology previously described by Place et al [10]. The 
149 following parameters were obtained before the control exercise and after the resistance strength 150 training session: (a) peak twitch $(\mathrm{Pt})$, i.e. the highest value of twitch tension production; (b) 151 contraction time $(\mathrm{Ct})$, i.e. the time from the origin of the mechanical response to $\mathrm{Pt}$; (c) half152 relaxation time (HRt), i.e. the time to obtain half of the decline in twitch maximal force.

153 Electromyographic activity of the right vastus lateralis (VL) muscle was monitored with surface 154 EMG during the single twitch. The subjects were prepared for placement of EMG electrodes by 155 shaving the skin of each electrode site, cleaning it carefully with alcohol wipe and lightly 156 abrading it to maintain a low inter-electrode resistance of $<1000 \Omega$. Pairs of $\mathrm{Ag} / \mathrm{AgCl}$ pre-gelled 157 surface electrodes (Medicotest, type Blue Sensor, Q-00-S, Denmark) of $40 \mathrm{~mm}$ diameter with a 158 center to center distance of $25 \mathrm{~mm}$ were placed on the VL muscle for EMG data acquisition. 159 According to SENIAM recommendations, the location of the electrode was place at the distal 2/3 160 point on the line from the anterior spina iliaca superior to the lateral side of the patella. A ground 161 electrode was placed on a bony site over the right anterior superior spine of the iliac crest. Peak162 to-peak amplitude (PPA), peak-to-peak duration (PPD) of the M-wave were determined for the 163 VL muscle during the control twitches performed before the MVC. Amplitude was defined as 164 the sum of absolute values for maximum and minimum points of the biphasic (one positive and 165 one negative deflection) $\mathrm{M}$ wave. Duration was defined as the time from maximum to minimum 166 points of the biphasic $\mathrm{M}$ wave. STATISTICAL ANALYSIS. - All data were expressed as mean \pm standard deviation (SD). A two-way 169 analysis of variance (group x session) for repeated measures was performed to analyze the effect 170 of groups and the strength training session using MVC, contractile properties, cadence and, 
171 oxygen uptake kinetics parameters as dependent variables. Tukey post-hoc test was used to

172 determine any differences among the Pre and Post fatiguing exercise and groups.

173 RESULTS

174 MVC FORCE AND CONTRACTILE PROPERTIES - No significant effect of 10 min cycling was observed 175 on the MVC in non-fatiguing $(\mathrm{Ctrl})$ and fatiguing conditions for the two groups.

176 A significant effect of ageing was observed on MVC with lower MVC values for masters than 177 young athletes $\left(\mathrm{MVC}_{\text {Fatigue pre }}:-30,2 \%\right.$ and $\left.\mathrm{MVC}_{\text {Fatigue Post }}:-27.4 \%\right)$. The difference between 178 young and master was also significant when MVC was expressed per unit free fat mass 179 (respectively for young and elderly MVC fatigue pre: $6.9 \pm 1.2$ vs. $5.2 \pm 1.5 \mathrm{~N} . \mathrm{kg}^{-1}$ free fat mass, $180 p<0.05)$. A significant decrease in MVC was measured after fatiguing exercise $(p<0.01)$ without 181 any difference between groups: - $13.4 \%$ for elderly adults and - $15.9 \%$ for young (figure 2 ).

182 A significant effect of ageing was observed on contractile properties before the heavy-fatiguing 183 exercise with a slower Ct and HRt for masters when compared to young athletes (for young and 184 elderly respectively; Ct: $55 \pm 15$ vs. $82 \pm 21 \mathrm{~ms}$ and HRt : $62 \pm 11$ vs. $82 \pm 18 \mathrm{~ms}, p<0.05$ ). After 185 fatigue a decrease in Pt was observed whatever the group without any changes in CT or HRt ($18624.5 \pm 3.8 \%$ and $-33 \pm 5.1 \%$ respectively for young and master athletes). No effects of group or 187 fatigue were observed on M-wave amplitude or duration (Table 1).

188 CADENCE - No effect of ageing was observed on the freely chosen cadence (FCC) during cycling 189 exercises before or after the strength training session exercise. After the strength training session 190 a significant increase in cadence was observed for both groups (respectively for young and 
191 master athletes: pre $v s$. post fatigue: $79.8 \pm 10.5 \mathrm{rpm}$ vs. $88.4 \pm 8.5 \mathrm{rpm}$ and $80.2 \pm 11.2 \mathrm{rpm}$ vs.

$19289.5 \pm 12.5 \mathrm{rpm})$.

193 OXYGEN UPTAKE KINETICS- Maximal oxygen uptake values were statistically higher in young 194 when compared with masters whatever the mode of expression (i.e. per unit body mass vs. per 195 unit fat free mass). When expressed per unit body mass, these values were respectively for

196 young and master athletes: $67 \pm 4 \mathrm{ml} \cdot \mathrm{min}^{-1} \cdot \mathrm{kg}^{-1}$ and $56 \pm 1 \mathrm{ml} \cdot \mathrm{min}^{-1} \cdot \mathrm{kg}^{-1}$. For the master group

197 these values were significantly higher than those previously reported in the literature in healthy 198 but untrained subjects [22]. No effect of ageing was observed on oxygen uptake kinetics 199 parameters during the control exercise. After fatigue a significant increase in oxygen slow 200 component and a decrease in time constant of the primary phase $\left(\begin{array}{l}1 \\ 1\end{array}\right)$ were observed in both 201 groups. (Table 2)

\section{DISCUSSION}

204 The present study aimed to analyze the age-related alteration of the knee extensor muscle 205 strength and oxygen uptake kinetics during cycling before and after a strength training session in 206 regularly endurance-trained subjects.

207 Main findings were 1) The maximal muscle strength capacity of endurance-trained masters was 208 lower than young athletes, but no significant effect was observed on oxygen uptake kinetics 2) 209 Following the resistance strength training session a significant effect of fatigue was observed on 210 muscle force and oxygen uptake kinetics in both groups, but no significant further effect of 211 ageing was observed on these alterations. 
213 generated $\sim 29 \%$ less voluntary isometric force compared to the young. This first result is in

214 accordance with the literature where a $\sim 15 \%$ to $\sim 35 \%$ decrease with age is classically observed

215 for trained and untrained subjects $[1,19,20]$, indicating that regular endurance training does not

216 allow to maintain the maximal muscular performance of elderly adults. In the literature, 60 years

217 old is generally the age where the decrease of maximal isometric strength capacity of the 218 quadriceps muscle is observed [33]. Reasons of this decrease are multi factorial and could be 219 linked to a reduction in muscle volume and cross-sectional area [29] or/and a change in size 220 numbers and proportions of muscle fiber type [25, 33]. These observations are supported by our 221 results on the twitch properties. In agreement with previous studies [5, 25], our data show a 222 slowing of the contraction time $(\mathrm{Ct})$ and half-relaxation time $(\mathrm{HRt})$ of the master compared with 223 young athletes $(\mathrm{Ct}:+33 \%$; HRt: $+43 \%)$. If many hypotheses have been suggested to explain this 224 slowing, the main explanation attributed this results to an age-related shift toward a higher 225 percentage of type I fiber, a loss of muscle fiber and motor units [12].

226 In this study we have observed a similar reduction in the maximal strength capacity for master 227 and young athletes after the strength training session, with a decrease in maximal strength of $228 \quad 15.9 \%$ for young and $-13.4 \%$ for older. In the literature the analysis of the effect of fatigue on 229 muscular properties has leaded to contradictory results. [27, 2]. For example during sustained 230 submaximal contractions, in healthy, but untrained subjects, Hunter et al [17] have compared 231 time to task failure for a sustained isometric contraction performed at a submaximal intensity 232 with elbow flexor muscles by young and old men who were matched for strength. They have 233 reported that time to task failure was longer for the old men compared with the strength-matched 
234 young men. On the opposite Baudry et al [2] have showed that the fatigability of the ankle 235 dorsiflexor muscles during repeated eccentric or concentric contractions was greater in untrained 236 elderly subjects than in young subjects. During repeated maximal contractions Petrella et al [10] 237 have reported that older adults are less capable of sustaining maximum concentric velocity 238 during repetitive contractions, indicating the role of contraction velocity in this impairment. In 239 our study we did not find any effect of ageing on contraction time or MVC reduction after 240 fatigue. These results suggest that fatigue is similar following exercise for both groups and 241 indicates that in regularly endurance-trained subjects the effect of ageing on force decrease is not 242 potentiated by fatigue.

243 OXYGEN UPTAKE KINETICS - One interesting result of this study is that in non-fatigued condition 244 no significant differences in oxygen uptake kinetics temporal parameters was observed between 245 our two groups. This observation seems to demonstrate that regular training could 246 counterbalance the well described slowing of oxygen uptake kinetics with ageing [3]. Pulmonary 247 oxygen uptake kinetics reflects the kinetics of adjustment of oxidative metabolism at the skeletal 248 level; therefore a decrease in this rate of adjustment would lead to a decrease in exercise capacity 249 and fatigue appearance. Relatively few studies have investigated the effect of training on oxygen 250 uptake kinetics in old subjects. A recent comparative study in master athletes has indicated that 251 oxygen uptake kinetics are faster in long distance runners than in middle distance or sprint 252 runners [4] suggesting an increase in oxidative capacity with endurance training. Moreover, in 253 middle age subjects ( $51 \pm 3$ years $)$ Fukoka et al., [13] have observed that oxygen uptake kinetics 254 are sensitive to a short endurance training program whereas effects on peak physiological 255 variables such as oxygen peak or hear rate peak appears later in the training program. Therefore 
256 the lack of any difference in primary time constant $\left({ }_{1}\right)$ values between young and master

257 athletes in our study is in agreement with these previous results and give an indirect evidence

258 that factors controlling oxygen uptake kinetics could be preserved by regular endurance training.

259 The second interesting result concerning oxygen uptake kinetics is that after fatigue the

260 amplitude of slow component was increased in both groups. The $\mathrm{VO}_{2}$ slow component indicates

261 that the efficiency with which the body uses oxygen to produce energy is progressively lost

262 while exercise continues at exactly the same speed and thus the $\mathrm{VO}_{2}$ slow component has been

263 described to be an important determinant of exercise tolerance [8]. To date only three studies has

264 compared oxygen slow component between young and old adults $[3,9,35]$. They have reported

265 an attenuation of the slow component amplitude in older compared to young untrained subjects.

266 One difficulty when interpreting these results between old and young subjects is that the smaller

267 slow component amplitude may be due to lower power in the older group. In our study we have

268 calculated the power output used for exercise relatively to each individual's ventilatory

269 thresholds. These values are similar in both groups and represents respectively for young and

270 elderly subjects: $81.4 \pm 1.6$ and $82.5 \pm 1.1 \% \mathrm{VO}_{2}$ peak. In non-fatigued or fatigued condition,

271 our results differ from previous studies since no differences in amplitude or time constant of the

272 slow component was observed between groups. Jones and Poole [18] have indicated that $86 \%$ of

273 the VO2 slow component is attributed to the exercising limbs and that the major contributor is

274 likely within the exercising muscle itself. In our study we found a similar alteration in muscular

275 performance after the strength training session in both groups. Thus the increase in $\mathrm{VO}_{2}$ slow

276 component could be mainly attributed to the muscular fatigue induced by exercise with an

277 additional recruitment of muscle fibres to maintain the same power output during cycling. Since 
278 the trained status of our subjects does not seems to protect the skeletal muscles from the decrease

279 in strength classically described with ageing, one surprising result of this study is that the slow 280 component increase after fatigue was not affected by ageing. This observation suggests a positive

281 effect of regular endurance training on exercise tolerance in master athletes. Further longitudinal 282 studies investigating muscular function in master athletes are necessary to explain this beneficial 283 effect.

284

285 CONCLUSION

286 Despite difference in maximal strength level and contractile properties between young 287 and master athletes, a similar effect of fatigue following the resistance strength training session 288 was observed in both groups. Furthermore no significant difference in oxygen uptake kinetics 289 was observed during cycling exercise between groups in control or fatigue condition. The present 290 study gives indirect evidence that regular endurance training could contribute to improve 291 exercise tolerance. 


\section{REFERENCES}

1. Allman BL, Rice CL. Incomplete recovery of voluntary isometric force after fatigue is not affected by old age. Muscle Nerve 2001; 24: 1156- 1167.

2. Baudry S, Malgorzata K, Pasquet B, Duchateau J. Age-related fatigability of the dorsiflexor muscles during concentric and eccentric contractions. Eur J Appl Physiol 2007; 100: 515-525.

3. Bell C, Paterson DH, Kowalchuk JM, Cunningham DA. Oxygen uptake kinetics of older humans are slowed with age but are unaffected by hyperoxia. Exp Physiol 1999; 84 :747759.

4. Berger NJ, Rittweger J, Kwiet A, Michaelis I, Williams AG, Tolfrey K, Jones AM. Pulmonary $\mathrm{O} 2$ uptake on-kinetics in endurance- and sprint-trained master athletes. Int J Sports Med 2006; $27: 1005-1012$

5. Bilodeau M, Henderson TK, Nolta BE, Pursley PJ, Sandfort G. Effect of aging on fatigue characteristics of elbow flexor muscles during sustained submaximal contraction. J Appl Physiol 2001; 91: 2654-2664

6. Bishop D, Jenkins DG, Mackinnon LT, McEniery M, Carey MF. The effects of strength training on endurance performance and muscle characteristics. Med Sci Sports Exerc 1999 ; $31: 886-891$

7. Brisswalter J, Bieuzen F, Giacomoni M, Tricot V, Falgairette G. Morning-to-evening differences in oxygen uptake kinetics in short-duration cycling exercise. Chronobiol Int 2007; 24:495-506. 
8. Carter H, Jones AM, Barstow TJ, Burnley M, Williams C, Doust JH. Effect of endurance training on oxygen uptake kinetics during treadmill running. J Appl Physiol 2000; 89: $1744-1752$.

9. Chick TW, Cagle Tg, Vegas FA Poliner JK, Murate GH. The effect of aging on submaximal performance and recovery. J Gerontol 1991; 46: B34-B38.

10. Coggan AR, Spina RJ, Rogers MA, King DS, Brown M, Nemeth PM, Holloszy JO: Histochemical and enzymatic characteristics of skeletal muscle in master athletes. J Appl Physiol 1990; 68: 1896-1901

11. Deley G, Kervio G, Van Hoecke J, Verges B, Grassi B, Casillas JM. Effects of a one-year exercise training program in adults over 70 years old: a study with a control group. Aging Clin Exp Res 2007; 19: 310-315.

12. Faulkner JA, Davis CS, Mendias CL, Brooks SV. The aging of elite male athletes: agerelated changes in performance and skeletal muscle structure and function. Clin J Sport Med 2008 ; 18: 501-507.

13. Fukuoka Y, Grassi B, Conti M, Guiducci D, Sutti M, Marconi C, Cerretelli P. Early effects of exercise training on on- and off-kinetics in 50-year-old subjects. Pflugers Arch 2002; 443: 690-697.

14. Gandevia SC. Spinal and supraspinal factors in human muscle fatigue. Physiol rev 2001; 81: $1725-1789$.

15. Hakkinen K, Keskinen KL. Muscle cross-sectional area and voluntary force production characteristics in elite strength- and endurance-trained athletes and sprinters. Eur J Appl Physiol Occup Physiol 1989; 59: 215-220. 
16. Hausswirth C, Lehénaff D, Dréano P, Savonen K. Effects of cycling alone or in a sheltered position on subsequent running performance during a triathlon. Med Sci Sports Exerc 1999; 31:599-604.

17. Hunter SK, Critchlow A, Enoka RM. Muscle endurance is greater for old men compared with strength-matched young men. J Appl Physiol. 2005 ; 99: 890-897.

18. Jones AM, Poole DC. Oxygen uptake dynamics: from muscle to mouth--an introduction to the symposium. Med Sci Sports Exerc $2005 ; 37: 1542-1550$.

19. Kent-Braun JA, Ng AV, Doyle JW, Towse TF. Human skeletal muscle responses vary with age and gender during fatigue due to incremental isometric exercise. J Appl Physiol 2002; 93: 1813-1823

20. Lanza IR, Russ DW, Kent-Braun JA. Age-related enhancement of fatigue resistance is evident in men during both isometric and dynamic tasks. J Appl Physiol 2004; 97: 967975

21. Lattier G, Millet GY, Martin A, Martin V. Fatigue and recovery after high-intensity exercise. Part II: Recovery interventions. Int J Sports Med 2004; 25: 509-515

22. Lepers R, Pousson M, Maffiuletti N, Martin A, Van Hoecke J. The effects of a prolonged running exercise upon strength characteristics. Int J Sports Med 2000; 21: 275-280.

23. Lepers R, Hausswirth C, Maffiuletti N, Brisswalter J, van Hoecke J Evidence of neuromuscular fatigue after prolonged cycling exercise. Med Sci Sports Exerc 2000; 32: 1880-1886.

24. Lepers R, Millet GY, Maffiuletti N, Hausswirth C, Brisswalter J. (2001) Effect of pedalling rates on physiological response during endurance cycling. Eur J Appl Physiol $2001 ; 85: 392-395$. 
25. Lexell J. Human aging, muscle mass, and fiber type composition. J Gerontol A Biol Sci Med Sci 1995; 50: 11-16.

26. Maharam LG, Bauman PA, Kalman D, Skolnik H, Perle SM. Masters athletes: factors affecting performance. Sports Med 1999; 28: 273-285

27. Macaluso A, De Vito G. Muscle strength power and adaptations to resistance training in older people. Eur J Appl Physiol 2004; 91: 450-472.

28. McNeil CJ, Rice CL. Fatigability is increased with age during velocity-dependent contractions of the dorsiflexors. J Gerontol A Biol Sci Med Sci 2007; 62: 624-629

29. Narici MV, Maganaris CN, Reeves ND, Capodaglio P. Effect of aging on human muscle architecture. J Appl Physiol 2003; 95: 2229-2234

30. Osteras H, Hoff J, Helgerund J. Effects of High-Intensity Endurance Training on Maximal Oxygen Consumption in Healthy Elderly People. J Appl. Gerontology 2005; 24: $377-387$.

31. Petrella JK, Kim JS, Tuggle SC, Hall SR, Bamman MM. Age differences in knee extension power, contractile velocity, and fatigability. J Appl Physiol. 2005 ;98 :211-220.

32. Place N., Maffiuletti N., Ballay Y., Lepers R. Twitch potentiation is greater after a fatiguing submaximal isometric contraction performed at short vs. long quadriceps muscle length. 2005; J Appl Physiol, 98 : 429-436.

33. Porter MM, Vandervoort AA, Lexell J. Aging of human muscle: structure, function and adaptability. Scand J Med Sci Sports 1995; 5: 129-142

34. Prud'Homme D, Bouchard C; Leblance C; Landry F; Lortie G; Boulay MR. Reliability of assessments of ventilatory thresholds. J Sports Sci, 1984 : 13-24. 
35. Sabapathy S, Schneider DA, Comadira G, Johnston I, Morris NR. Oxygen uptake kinetics during severe exercise: a comparison between young and older men. Respir Physiol Neurobiol 2004; 139: 203-213.

36. Sultana F., Brisswalter J., Lepers R., Hausswirth C., Bernard T. Effects of age and gender on Olympic Triathlon performances. Sci Sports $2008 ; 23: 130-135$.

37. Tanaka H, Seals DR. Endurance exercise performance in masters athletes: age-associated changes and underlying physiological mechanisms. J Physiol. 2008; 586: 56-63.

38. Tarpenning KM, Hawkins SA, Marcell TJ, Wiswell RA. Endurance exercise and leg strength in older women. J Aging Phys Act 2006; $14: 3-11$.

39. Trappe S. Marathon runners: how do they age? Sports Med 2007; 37: 302-305.

40. Wasserman K, Whipp BJ, Koyl SN, Beaver WL. Anaerobic threshold and respiratory gas exchange during exercise. J Appl Physiol 1973; 35: 236-243

41. Whipp BJ. The slow component of O2 uptake kinetics during heavy exercise. Med Sci Sports Exerc 1994; 26: 1319-1326. 
Table 1 Muscular twitch and vastus lateralis muscle M-wave characteristics (peak twitch, i.e. Pt; contraction time, i.e. $\mathrm{Ct}$; half-relaxation time, i.e. HRt; peak to peak amplitude, i.e. PPA; peak to peak duration, i.e. PPD) before and after the fatiguing exercise for masters and young groups.

\begin{tabular}{|c|c|c|c|c|c|c|}
\hline \multirow[b]{2}{*}{ Groups } & \multirow[b]{2}{*}{ Period } & \multicolumn{3}{|c|}{ Twitch } & \multicolumn{2}{|c|}{ M-Wave } \\
\hline & & $\begin{array}{l}\mathrm{Pt} \\
(\mathrm{N})\end{array}$ & $\begin{array}{c}\mathrm{Ct} \\
(\mathrm{ms})\end{array}$ & $\begin{array}{l}\text { HRt } \\
(\mathrm{ms})\end{array}$ & $\begin{array}{l}\text { PPA } \\
(\mathrm{mV})\end{array}$ & $\begin{array}{l}\text { PPD } \\
(\mathrm{ms})\end{array}$ \\
\hline \multirow[t]{2}{*}{ Young } & before & $50.6 \pm 12.6$ & $55 \pm 15$ & $62 \pm 11$ & $14.6 \pm 4.5$ & $5.7 \pm 1.4$ \\
\hline & after & $38.2 \pm 21.2^{*}$ & $49 \pm 18$ & $56 \pm 14$ & $13.6 \pm 5.2$ & $5.3 \pm 1.8$ \\
\hline \multirow[t]{2}{*}{ Elderly } & before & $46.2 \pm 8.6$ & $82 \pm 21^{\dagger}$ & $82 \pm 18^{\dagger}$ & $16.6 \pm 9.7$ & $6.2 \pm 1.2$ \\
\hline & after & $33.6 \pm 12.4^{*}$ & $73 \pm 15^{\dagger}$ & $78 \pm 21^{\dagger}$ & $17.1 \pm 10.2$ & $6.3 \pm 1.8$ \\
\hline
\end{tabular}

Values are mean $\pm \mathrm{SD} .{ }^{*}$ when a difference between the two periods was significant at $\mathrm{p}<0.05$; $\dagger$ when a difference between the two groups was significant at $\mathrm{p}<0.05$. 
Table 2 Parameters of oxygen kinetics before and after fatiguing exercise in young and master athletes.

\begin{tabular}{cccccc}
\hline \hline Groups & Period & $\tau 1$ & A1 & $\tau 2$ & A2 \\
& & $(\mathrm{s})$ & $(\mathrm{ml} . \mathrm{min}-1)$ & $(\mathrm{s})$ & $(\mathrm{ml} . \mathrm{min}-1)$ \\
\hline Young & before & $25.1 \pm 12$ & $2622 \pm 365$ & $188 \pm 68$ & $214 \pm 54$ \\
\hline \multirow{2}{*}{ Elderly } & after & $21.6 \pm 13^{*}$ & $2805 \pm 495^{*}$ & $198 \pm 34$ & $295 \pm 48^{*}$ \\
\hline & before & $27.8 \pm 10.2$ & $2384 \pm 321$ & $218 \pm 52$ & $231 \pm 74$ \\
\hline \hline
\end{tabular}

Values are mean $\pm \mathrm{SD} .{ }^{*}$ when a difference between the two periods was significant at $\mathrm{p}<0.05$

A1 and A2 represent the primary and slow component amplitudes, $\tau 1$ and $\tau 2$ the time constants of the kinetics 
Figure 1 - Graphic representation of the experimental protocol. CTRL, Control cycling session; VO2max, maximal oxygen uptake test; MVC, maximal voluntary contraction; 1RM, one moreRepetition-Maximal ; R, rest

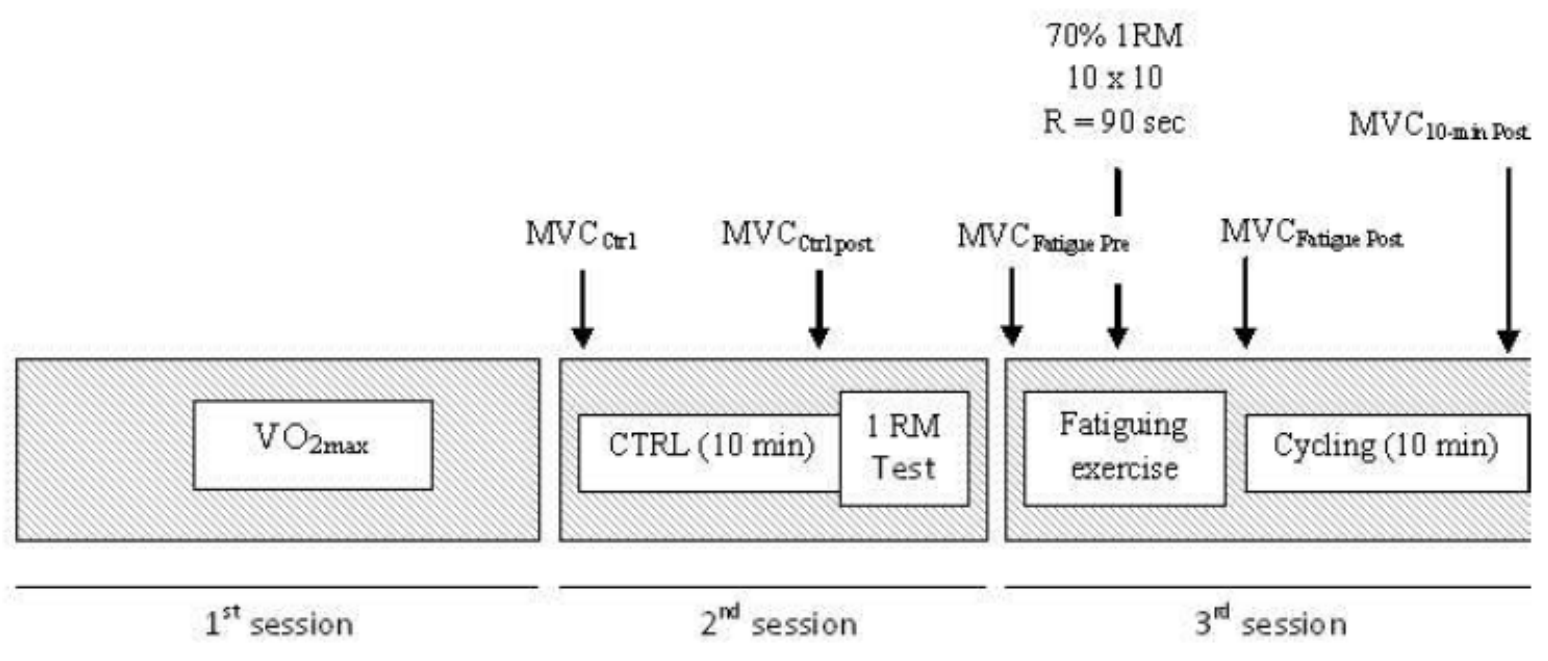


Figure 2 - MVC of the knee extensors measured immediately before $\left(\mathrm{MVC}_{\mathrm{Ctrl}}\right)$ the control cycling test, before $\left(\mathrm{MVC}_{\mathrm{Fatigue} \mathrm{Pre}}\right)$ and after the fatiguing exercise $\left(\mathrm{MVC}_{\mathrm{Fatigue} \mathrm{Post}}\right)$ and after the cycling exercise ( $\left.\mathrm{MVC}_{\text {Cycling Post }}\right)$. Values expressed are means $\pm \mathrm{SE}$.

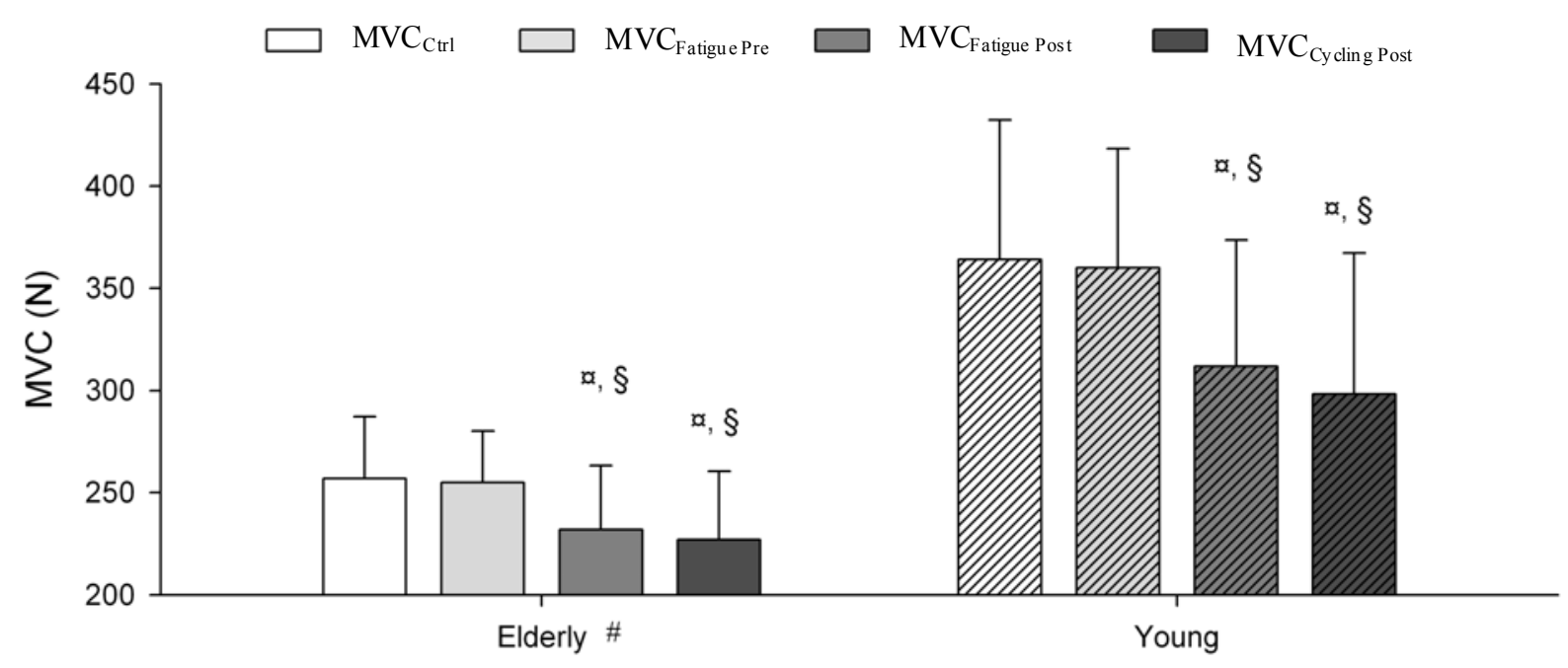

, significantly different from $\mathrm{MVC}_{\mathrm{Ctrl}}(p<0.05)$

$\S$, significantly different from $\operatorname{MVC}_{\text {Fatigue pre }}(p<0.05)$

\#, significantly different from Young subjects $(p<0.05)$ 